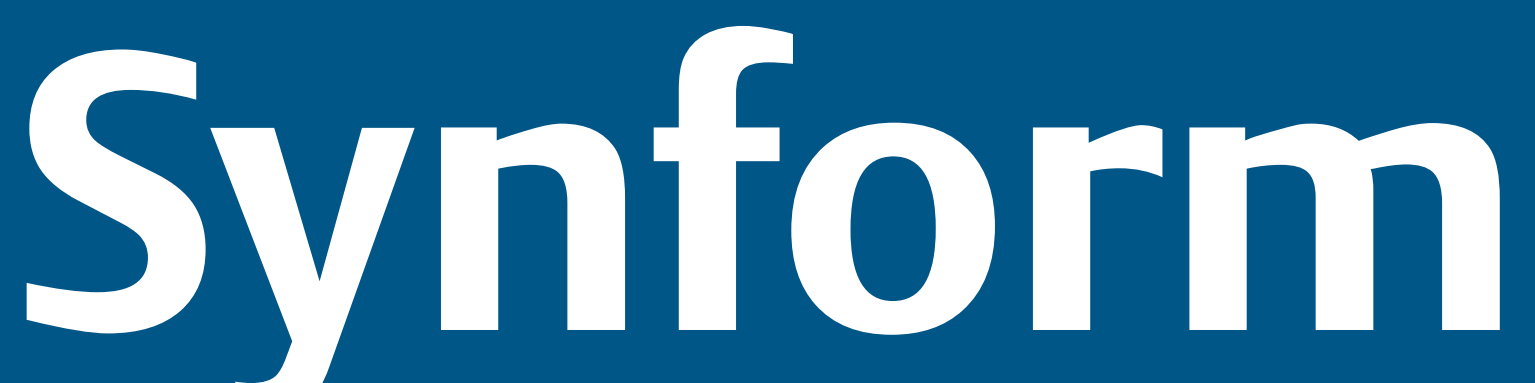

People, Trends and Views in Chemical Synthesis

$$
\text { 2022/01 }
$$

\title{
Photomediated Ring Contraction of Saturated Heterocycles
}

Highlighted article by J. Jurczyk, M. C. Lux, D. Adpressa, J. F. Kim, Y.-H. Lam, C. S. Yeung, R. Sarpong
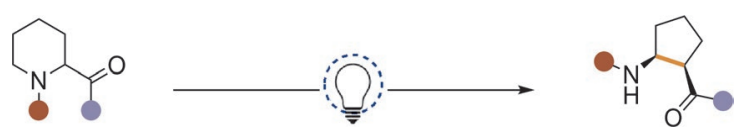

\section{Contact}

Your opinion about Synform is welcome, please correspond if you like:

marketing@thieme-chemistry.com
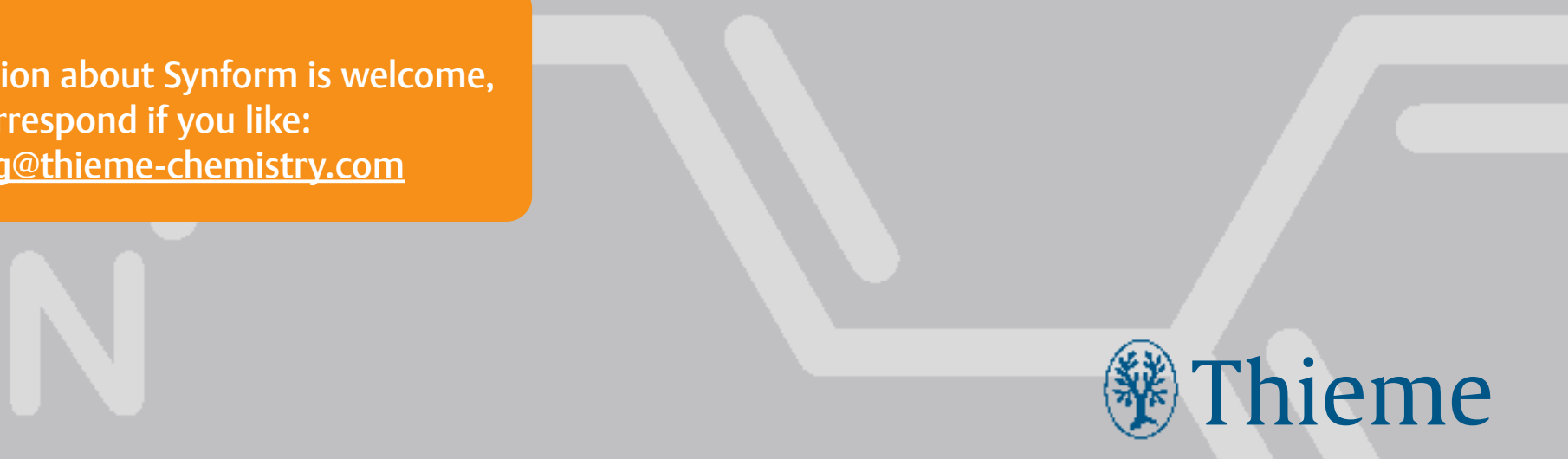


\section{Dear Readers,}

I am delighted to introduce a new year of SYNFORM with an absolutely first-class January issue, packed full of great science, published in top-notch journals. If a good beginning bodes well, it is safe to say that we have a very exciting year ahead. The critical duty of kicking off this season is on the shoulders of Y. Nagata (Japan) who is the protagonist - and past Thieme Chemistry Journals Awardee - of our Young Career Focus interview, which zooms in on robot-assisted synthesis and stereochemical properties of polymers in solution. The first Literature Coverage article covers a recent ground-breaking publication in Science by the group of R. Sarpong (USA) on a photo-mediated ring contraction of saturated heterocycles, such as piperidines, cyclic ethers and thioethers, which allows for the skeletal editing of complex cyclic organic molecules. The next Literature Coverage article covers another recent Science paper, authored by the group of W. Han (P. R. of China), on a conceptually new approach to the notoriously challenging selective oxidation of phenols, which has been achieved via iron-catalysed non-directed arene $\mathrm{C}-\mathrm{H}$ hydroxylation, enabled by L-cystinederived ligands inspired by cytochrome P450 enzymes. The fourth and final article of this pyrotechnic issue covers a new approach - developed through a collaboration involving the groups of M. Bradley (UK) and J. Geng (P. R. of China), and published in Nat. Chem. for activating prodrugs using radiotherapy, and specifically X-rays, which holds great promise for future clinical applications.

Happy New Year and enjoy your reading!

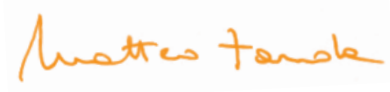

\section{In this issue}

Young Career Focus

Young Career Focus: Professor Yuuya Nagata

(Hokkaido University, Sapporo, Japan)

Literature Coverage

Photomediated Ring Contraction of Saturated Heterocycles

Literature Coverage

Iron-Catalyzed Arene C-H Hydroxylation

Literature Coverage

Switching On Prodrugs Using Radiotherapy. ...

Coming soon

\section{Contact}

If you have any questions or wish to send feedback, please write to Matteo Zanda at: synform@outlook.com 


\section{Young Career Focus: Professor Yuuya Nagata (Hokkaido University, Sapporo, Japan)}

Background and Purpose. SYNFORM regularly meets young up-and-coming researchers who are performing exceptionally well in the arena of organic chemistry and related fields of research, in order to introduce them to the readership. This Young Career Focus presents Professor Yuuya Nagata (Hokkaido University, Sapporo, Japan).

\section{Biographical Sketch}

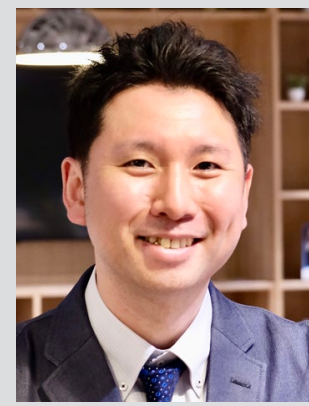

Prof. Y. Nagata
Yuuya Nagata was born in 1980 in Kagawa, Japan. He received his B.Sc. and Ph.D. degrees from Kyoto University (Japan) in 2003 and 2008, respectively, under the supervision of Prof. Yoshiki Chujo. In April of 2008, he worked at Kyoto University as a postdoctoral fellow in the group of Prof. Yoshiki Chujo for a month. In May of 2008, he joined the group of Prof. Michinori Suginome at Kyoto University as an assistant professor. In December of 2019, he joined the Institute for Chemical Reaction Design and Discovery (ICReDD) at Hokkaido University (Sapporo, Japan) as a specially appointed associate professor. His research interests are in organic synthesis, polymer science, theoretical chemistry, and automated synthesis using robots.

\section{INTERVIEW}

SYNFORM What is the focus of your current research activity?

Prof. Y. Nagata My current interest is focused on organic synthesis using robots. So far, robotic synthesis has been used for high-throughput screening; however, it is still difficult to cover all combinations of substrates and reaction conditions. We are now working on theoretical chemistry and cheminformatics to be applied to robotic synthesis. I believe that this approach will make organic chemistry smarter and more successful.

\section{SYNFORM When did you get interested in synthesis?}

Prof. Y. Nagata I became interested in chemical synthesis and chemistry in general - when I was at elementary school. I read some books to carry out quite simple experiments, such as beautiful color changes in an extract of a flower by adding vinegar or soapy water. I felt at first it was a sort of magic, and then I became interested in the detailed mechanism of color change reactions. That was the starting point for my interest in organic synthesis.

SYNFORM What do you think about the modern role and prospects of organic synthesis?

Prof. Y. Nagata In recent years, the role of organic synthesis has been growing in importance in various fields. In particular, I consider that organic chemistry should make a greater contribution to environmental preservation. To date, organic chemistry has produced various artificial chemicals, which sometimes cause environmental pollution. Therefore, organic chemists have a responsibility to solve this kind of problem. For example, the development of biodegradable plastics, carbon dioxide fixation, and energy-efficient chemi- 
cal transformations will contribute to environmental preservation via organic chemistry.

SYNFORM Could you tell us more about your group's areas of research and your aims?

Prof. Y. Nagata Our group will demonstrate the importance of artificial intelligence in chemical reaction design and discovery using an automated robotic system designed for organic synthesis, which can quickly validate new chemical reactions suggested by the artificial intelligence. We also aim to build a framework that automatically evaluates unknown reaction products with multiple analytical instruments, which are directly connected to the robot, and accumulates the experimental results as a database.

SYNFORM What is your most important scientific achievement to date and why?

Prof. Y. Nagata Before I moved to my current position, I worked on the control of chirality of helical polymers, poly(quinoxaline-2,3-diyl)s. Although we found that the polymer, having chiral side chains, exhibits a helix inversion dependent on the solvent (e.g., right-handed helix in tetra- hydrofuran (THF) and left-handed helix in 1,1,2-trichloroethane) in 2010, its detailed mechanism had not yet been clarified. ${ }^{1,2}$ In 2018, we got the chance to collaborate with physicists in quantum beam science and the structures of the polymer in solution were revealed, allowing us to investigate the mechanism of the helix inversion (Figure 1 ). ${ }^{3}$ This study firstly revealed that a small difference in solvent effect can cause a large structural change of the helical main chain. Furthermore, I would like to emphasize that neutron beam science, which is unfamiliar in synthetic organic chemistry, was very powerful and useful in this research project.

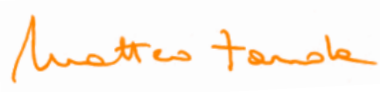

\section{REFERENCES}

(1) T. Yamada, Y. Nagata, M. Suginome Chem. Commun. 2010, 46, 4914-4916.

(2) Y. Nagata, T. Yamada, T. Adachi, Y. Akai, T. Yamamoto, M. Suginome J. Am. Chem. Soc. 2013, 135, 10104-10113. (3) Y. Nagata, T. Nishikawa, M. Suginome, S. Sato, M. Sugiyama, L. Porcar, A. Martel, R. Inoue, N. Sato J. Am. Chem. Soc. 2018, 140, 2722-2726.

(a)

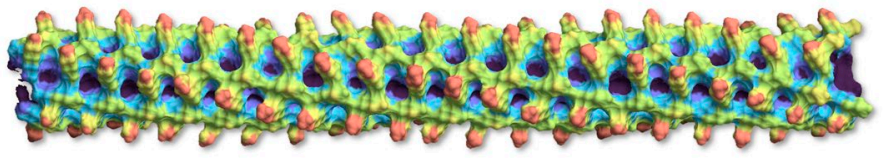

Right-handed helix in THF-d 8

(b)

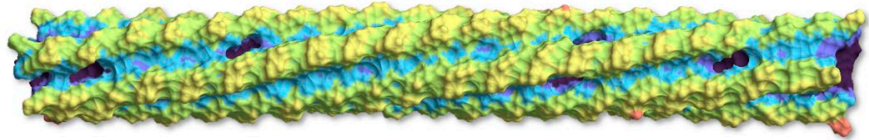

Left-handed helix in 1,1,2-trichloroethane- $d_{3} /$ THF- $d_{8}(4: 1, v / v)$

Figure 1 The solvent-excluded surfaces of poly(quinoxaline-2,3-diyl) having (R)-2-octyloxymethyl side chains revealed by smallangle neutron scattering measurements. (a) Right-handed helical structure in THF- $d_{8}$. (b) Left-handed helical structure in 1,1,2-trichloroethane- $d_{3} /$ THF- $d_{8}(4: 1, v / v)$. 


\title{
Photomediated Ring Contraction of Saturated Heterocycles
}

\author{
Science 2021, 373, 1004-1012
}

Skeletal editing, the precise manipulation of a molecule's core scaffold, especially at the single atom level, is an emerging concept of importance in organic chemistry. ${ }^{1}$ Recent reports in this area have included nitrogen deletion, ${ }^{2}$ single-atom insertion, ${ }^{3}$ and ring contractions. ${ }^{4}$ Through a collaboration involving researchers at the University of California-Berkeley in Prof. Richmond Sarpong's laboratory and at the research labs of Merck \& Co., Inc., Kenilworth, NJ, USA - known as MSD outside of the US and Canada - a light-mediated ring contraction of saturated six-membered heterocycles to five-membered rings that relocates the heteroatom from an endocyclic to exocyclic position has been achieved. This academia/industry partnership started as part of the "Disruptive Chemistry" initiative at MSD - an effort focused on developing enabling chemical reactions of importance for industrial applications, including novel scaffold changes to precisely edit molecules. "Disruptive Chemistry is an initiative within MSD where we took action in addressing unmet synthetic needs through academic partnerships. The collaboration between MSD and Berkeley was one key pillar of that strategy, and together with Richmond's lab, we were able to make major inroads in the area of bicyclic amine synthesis and molecular editing," said Dr. Charles Yeung. As part of this collaboration, the Sarpong group (graduate students Justin Jurczyk and Sojung Kim) and scientists at MSD (Dr. Charles Yeung, Dr. Michaelyn Lux, Dr. Colin Lam, and Dr. Donovon Adpressa) worked productively on several projects, including the synthesis of bicyclic amines ${ }^{5,6}$ and piperidine peripheral functionalization. ${ }^{7}$ Building on insights from their Pd-catalyzed piperidine functionalization research, they reasoned that $\alpha$-benzoylated piperidine scaffolds could undergo further diversification using the photoactive benzoyl group. Indeed, initial reactions on these acylated frameworks (see I, Scheme 1B) were anticipated to yield Norrish-Yang type azetidinol products (e.g., III). However, upon irradiation, cis-cyclopentyl amine II, whose initial structure was elucidated by Dr. Adpressa, was observed as the major product. "We recognized the importance of this transformation, as - in the context of piperidines - this single-step reaction transforms the core structure of the saturated aza-cycle in an unconventional manner, affording a cyclopentyl amine in the process," said Professor Sarpong. He continued: "It also represented a form of skeletal editing, much like the earlier accounts from Seebach and Suárez (Scheme 1A), ${ }^{8,9}$ on using ring-opening and subsequent ring-closure to effect the relocation of a hetero- atom to the periphery of a ring (Scheme 1B). The optimization and extension of the transformation to other aliphatic heterocyclic structural motifs were therefore pursued."

Justin Jurczyk and Dr. Lux undertook an extensive screening of solvent, wavelength, and concentration to optimize the transformation. In addition, they examined different protecting groups on the piperidine substrates and observed that sulfonyl groups (e.g. IV, Scheme 1C) worked well, whereas other common groups on nitrogen resulted in lower yields and diminished reactivity under the optimized conditions. Dr. Lux explained: "To overcome this issue, we employed the high-throughput experimentation (HTE) capabilities at MSD to identify an additive that improved the yield of the ringcontraction products for non-sulfonamide substrates (e.g., V). 3-Cyanoumbelliferone was identified as a suitable additive that led to improved efficiency in the conversion of several non-sulfonyl piperidines."

Next, the team embarked on expanding the reaction beyond piperidine frameworks and explored a diverse set of alternative photoactive ketone auxiliaries. "Overall, the optimized reaction conditions were found to be general for a broad range of substrates, including cyclic ethers (e.g. VI) and thioethers, and benzannulated aliphatic cyclic heterocycles (VII)," explained Dr. Yeung. He continued: "Additionally, in the exploration of ketone auxiliaries, it was observed that a range of aromatic ketones worked well in this capacity. To expand the scope beyond aromatic ketones, Justin Jurczyk and Dr. Lux examined aliphatic ketones (e.g. VIII), which required UV light rather than $400 \mathrm{~nm}$ light sources and extended the scope to alkenyl and alkynyl ketones - ultimately showing that nonaryl ketones were effective auxiliaries albeit less efficient." More complex, biologically relevant, molecules were then examined. Several scaffolds, including a peptide residue (IX) and a mefloquine derivative $(\mathbf{X})$ also participated in this transformation. "Given the complexity of the products that were obtained, comprehensive structural elucidation, performed by Dr. Adpressa, was conducted," added Dr. Yeung.

Early in the collaboration, in parallel with the experimental work, the team also leveraged the computational chemistry capabilities at MSD to accelerate reaction development through an in-depth investigation of reaction mechanism and stereoselectivity. "One of the most interesting results from the calculations was that the transition state energies for the intramolecular Mannich step correlated with the cis/trans 
ratios observed experimentally ( $\Delta \Delta \mathrm{G}^{\ddagger}$ on the order of $1 \mathrm{kcal} /$ mol)," remarked Professor Sarpong. He continued: "The energy differences could be rationalized by a shorter and stronger hydrogen bond as well as a more staggered arrangement of substituents about the forming $\mathrm{C}-\mathrm{C}$ bond in the cis-productyielding transition state (Scheme 2A)." The more pronounced photoreactivity of the starting material compared to the product was also supported by experimentally measured and DFT calculated absorption profiles ( $\mathrm{n} \rightarrow \pi^{*}$ transition) (Scheme 2B). "Here, selective irradiation of the starting material could be achieved because of the hypsochromic shift of absorbance for the product relative to the starting material, as well as a decrease in molar absorptivity for the product," said Dr. Lam, who added: "This collaboration is a very nice illustration of how DFT calculations can impact organic reaction development in an industrial setting. They are not only important academically, but also increasingly often applied, in real-time collaboration with chemists, to support a wide range of investigations in both drug discovery and pharmaceutical development, including route planning, drug/catalyst design, mechanistic studies, structural elucidation, and other areas."
Given the insights into the observed diastereoselectivity of the ring contraction (stemming from a highly organized transition state from an achiral imine-enol intermediate), Justin Jurczyk, Sojung Kim, and Dr. Lux investigated an enantioselective variant of the ring contraction reaction. BINOL-derived chiral phosphoric acids were identified as effective catalysts that led to the formation of ring contraction products in up to $90 \%$ ee (conversion of XI into XII, Scheme 2C).

Reflecting on the collaboration, Professor Sarpong said: "This is an exciting example of an academic-industry collaboration that highlighted a key need for diversifying chemical space, especially of saturated heterocycles. The current work came about as the result of a productive and sustained collaboration between the groups at Berkeley and at MSD over several years. The groundwork was set with our earlier work, ${ }^{7}$ which then evolved to a broader interest in the Norrish-Yang reaction. The work in the Science paper is a combination of a deep command of what had been reported in the literature and serendipity. Careful experimentation, computational analysis, and structural elucidation led to the identification of the optimal conditions that we report. There is still a lot to

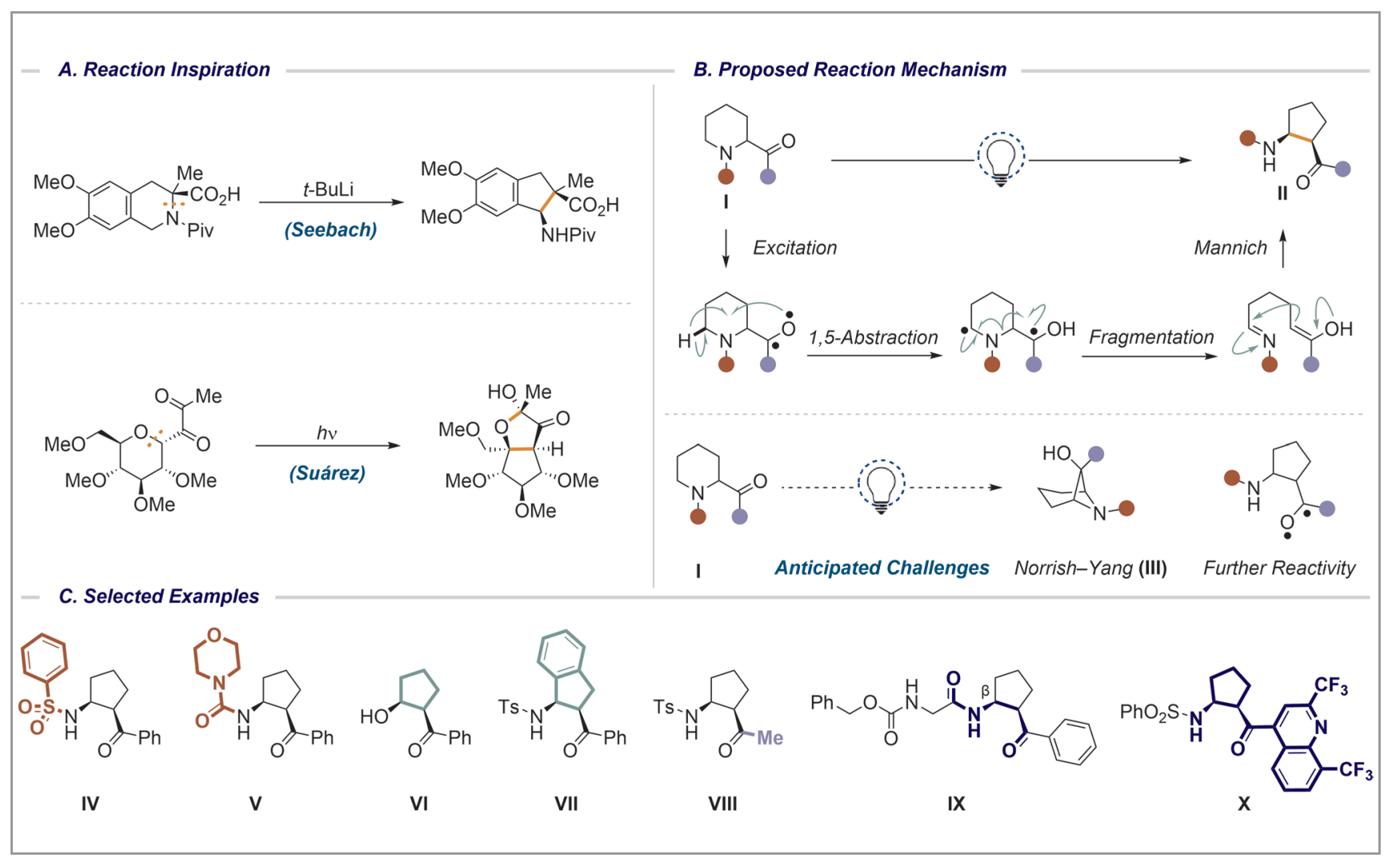

Scheme 1 Highlights of the Science paper 


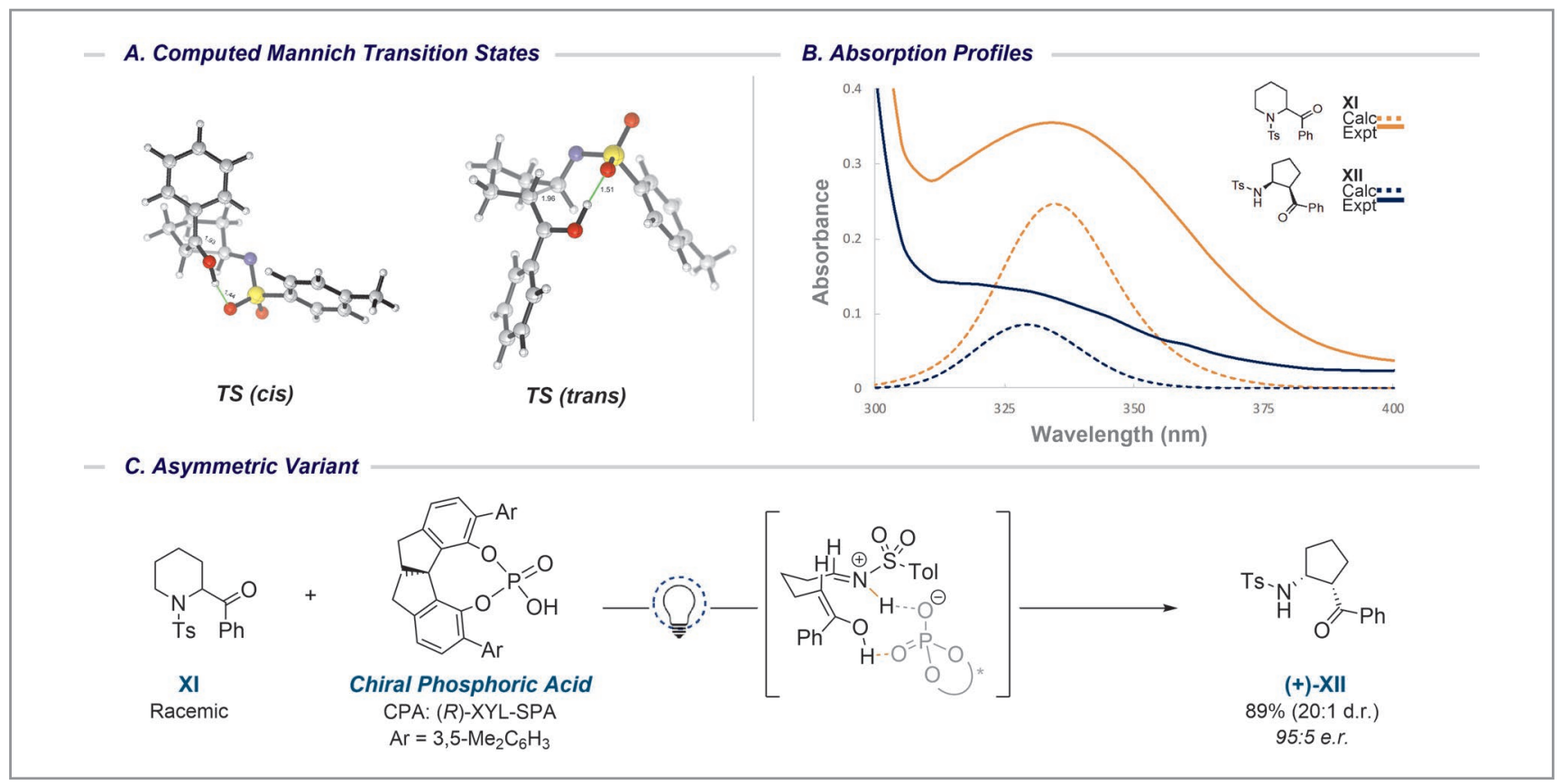

Scheme 2 Computational insight and development of an asymmetric contraction variant

be done in this area." He concluded: "We are optimistic about the application of this method not only to diversification of the core structures of pharmaceutically and agrochemically relevant compounds, but also to complex molecule synthesis and the preparation of light-responsive materials."

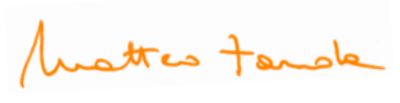

\section{REFERENCES}

(1) K. R. Campos, P. J. Coleman, J. C. Alvarez, S. D. Dreher, R. M. Garbaccio, N. K. Terrett, R. D. Tillyer, M. D. Truppo,

E. R. Parmee Science 2019, 363, eaat0805.

(2) S. H. Kennedy, B. D. Dherange, K. J. Berger, M. D. Levin Nature 2021, 593, 223-227.

(3) B. D. Dherange, P. Q. Kelly, J. P. Liles, M. S. Sigman, M. D. Levin J. Am. Chem. Soc. 2021, 143, 11337-11344.

(4) J. Jurczyk, M. C. Lux, D. Adpressa, S. F. Kim, Y.-H. Lam, C. S. Yeung, R. Sarpong Science 2021, 373, 1004-1012.

(5) M. C. Lux, J. Jurczyk, Y.-h. Lam, Z. J. Song, C. Ma, J. B. Roque, J. S. Ham, N. Sciammetta, D. Adpressa, R. Sarpong, C. S. Yeung Org. Lett. 2020, 22, 6578-6583.

(6) J. S. Ham, B. Park, M. Son, J. B. Roque, J. Jurczyk,

C. S. Yeung, M.-H. Baik, R. Sarpong J. Am. Chem. Soc. 2020, 142, 13041-13050.

(7) J. B. Roque, Y. Kuroda, J. Jurczyk, L.-P. Xu, J. S. Ham,

L. T. Göttemann, C. A. Roberts, D. Adpressa, J. Saurí, L. A. Joyce,

D. G. Musaev, C. S. Yeung, R. Sarpong ACS Catal. 2020, 10, 2929-2941.

(8) T. Gees, W. B. Schweizer, D. Seebach Helv. Chim. Acta 1993, 76, 2640-2653.

(9) D. Álvarez-Dorta, E. I. León, A. R. Kennedy, C. RiescoFagundo, E. Suárez Angew. Chem. Int. Ed. 2008, 47, 89178919. 


\section{About the authors}

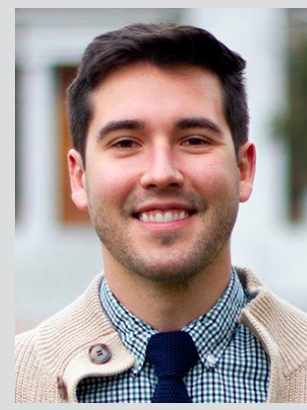

J. Jurczyk

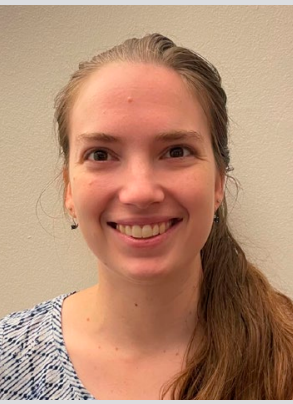

Dr. M. C. Lux
Justin Jurczyk was born in New Jersey (USA) and completed his B.S. in chemistry at Allegheny College, Pennsylvania (USA) under the direction of Prof. Ryan Van Horn. He then moved to the San Francisco Bay Area (USA) and is currently working toward his Ph.D. in chemistry at the University of California, Berkeley (USA) under the supervision of Prof. Richmond Sarpong. Here, his studies focus on the development of strategies aimed at saturated cyclic amine diversification.

Michaelyn C. Lux was born in Michigan (USA) and completed her B.Sc. in chemistry at Michigan State University (USA); she continued to Ph.D. studies as part of the Tri-Institutional PhD Program in chemical biology under the supervision of Prof. Derek Tan where she worked on Pd-catalyzed domino reactions to form bicyclic ethers. She continued to postdoctoral studies as part of the MRL postdoctoral program under the mentorship of Dr. Charles Yeung and worked on the synthesis of bridged bicyclic amines and skeletal editing of piperidines. She is currently a Senior Scientist in Discovery Chemistry at Merck \& Co., Inc., Kenilworth, NJ, USA.

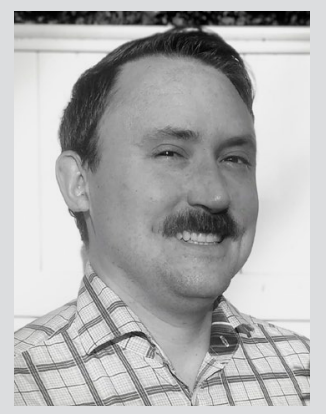

Dr. D. Adpressa
Donovon Adpressa was born in California (USA) and completed his Ph.D. in chemistry at Oregon State University (USA) with a focus on the discovery and structure elucidation of novel natural products, under the mentorship of Prof. Sandra Loesgen. Donovon has continued to pursue his passion for structure elucidation as a Senior Scientist in Analytical Research \& Development at Merck \& Co., Inc., Kenilworth, NJ, USA.

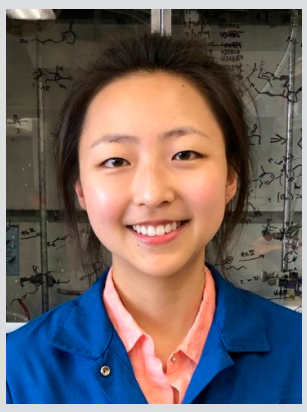

Sojung F. Kim was born in California (USA) and completed her B.S. in chemistry at The Pennsylvania State University (USA) under the direction of Professor Thomas E. Mallouk and Professor Xin Zhang. She is currently living in the San Francisco Bay Area (USA) and working toward her Ph.D. in chemistry at the University of California, Berkeley (USA) under the supervision of Professor Richmond Sarpong. Her studies currently focus
and saturated cyclic amines and en-

S. F. Kim on skeletal editing strategies of saturated cyclic
antioselective transformations of iminium ions.

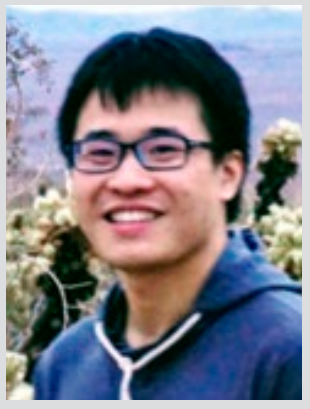

Yu-hong (Colin) Lam received his undergraduate and doctoral training in organic synthesis (with Prof. Véronique Gouverneur) at Oxford University (UK) and conducted postdoctoral studies in computational chemistry (with Prof. Ken Houk) at UCLA (USA). He is an Associate Principal Scientist at Merck \& Co., Inc., Kenilworth, NJ, USA. and co-chair of the Dr. Y.-h. Lam Computational Chemistry Working Group of the International Consortium for Innovation and Quality in Pharmaceutical Development. He specializes in the practical applications of quantum chemical calculations to support both drug discovery and process development.

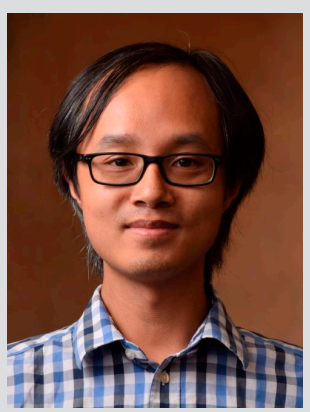

Charles S. Yeung completed his B.Sc. (Honours) at the University of British Columbia (Canada), Ph.D. at the University of Toronto (Canada) under the guidance of Prof. Vy Dong, specializing in using transition-metal catalysis to activate $\mathrm{CO}_{2}$ and $\mathrm{C}-\mathrm{H}$ bonds, and postdoctoral fellowship at Harvard University (USA) with Prof. Eric Jacobsen, innovating in asymmetric reactions catalyzed by hydrogen bonding catalysts. Charles is currently

Dr. C. S. Yeung an Associate Principal Scientist in Discovery Chemistry at Merck \& Co., Inc., Kenilworth, NJ, USA, and was one of three Disruptive Chemistry Fellows involved in a long-term academia-industry partnership tackling bicyclic amine synthesis and molecular editing. Charles' interests include neuroscience, oncology, targeted protein degradation, catalysis, and HTE. 


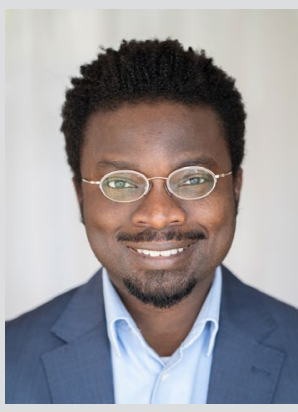

Prof. R. Sarpong
Richmond Sarpong is a Professor of Chemistry at the University of California, Berkeley (USA) where he and his group specialize in synthetic organic chemistry. Richmond became interested in chemistry after seeing, firsthand, the effectiveness of the drug ivermectin in combating river blindness during his childhood in Ghana, West Africa. Richmond described his influences and inspirations in a TEDxBerkeley talk in 2015 (Face of
Disease in Sub-Saharan Africa - https://www.youtube.com/ watch?v=nlsY87-zkXA). Richmond completed his undergraduate studies at Macalester College in St. Paul, MN (USA) with Prof. Rebecca C. Hoye and his graduate work was carried out with Prof. Martin F. Semmelhack at Princeton University (USA). He conducted postdoctoral studies at Caltech (USA) with Prof. Brian M. Stoltz and began at Berkeley in 2004. 


\title{
Iron-Catalyzed Arene C-H Hydroxylation
}

\author{
Science 2021, 374, 77-81
}

Phenols are among the most important precursors for the manufacture of pharmaceuticals, dyes, and functional polymers. The group of Professor Wei Han at Nanjing Normal University (P. R. of China) has been investigating novel, more efficient and greener methods to produce functionalized phenols from readily available starting materials. Professor Han said: "Benzene $\mathrm{C}-\mathrm{H}$ hydroxylation is generally regarded as the most straightforward and direct of all approaches to phenol. However, direct and selective conversion of benzene into phenol with molecular oxygen as oxidant is referred to as one of the 'ten challenges for catalysis' because the $\mathrm{C}-\mathrm{H}$ bond dissociation energy (BDE) of benzene is high (ca. $470 \mathrm{~kJ} / \mathrm{mol}$ ), thus phenol is far more reactive toward oxidation than benzene itself, producing over-oxygenated by-products. Moreover, substituted benzenes usually lead to an inseparable mixture of constitutional isomers and - among them - alkylarenes preferentially undergo oxidation of the $\mathrm{sp}^{3} \mathrm{C}-\mathrm{H}$ bonds in the aromatic side-chains (which have lower BDE, ca. $375 \mathrm{~kJ} / \mathrm{mol}$ ) rather than oxidizing the $\mathrm{sp}^{2} \mathrm{C}-\mathrm{H}$ bonds in the aromatic ring."

Although transition-metal-catalyzed chelation-assisted $\mathrm{C}-\mathrm{H}$ hydroxylation of arenes has been reported previously, leading to an improvement of both selectivity and reactivity of this kind of approach to phenols, the strategy often requires pre-installed directing groups, which makes only ortho-hydroxylation attainable. "Non-directed arene $\mathrm{C}-\mathrm{H}$ hydroxylation can reach sites that are currently inaccessible by a directed approach; however, besides the issues mentioned above, an excess of arene is frequently required to ensure sufficient reactivity," explained Professor Han. He continued: "To obviate the need for directing groups and excess arene, an alternative strategy to access phenols would be the use of a pre-formed stable intermediate via aromatic $\mathrm{C}-\mathrm{H}$ borylation, silylation, thianthrenation, or oxygenation, followed by additional steps to give the phenols (Scheme 1)."

Professor Han noted that cytochrome P450 enzymes are capable of hydroxylation of strong aryl $\mathrm{C}-\mathrm{H}$ bonds in the absence of directing groups with high selectivity, and have an active site that consists of an iron porphyrin cofactor. "Cytochrome P450-bioinspired enzymatic catalysis relies on the design and synthesis of porphyrin and porphyrinoid ligands (Scheme 2). However, these bioinspired methods for non-directed arene $\mathrm{C}-\mathrm{H}$ hydroxylation are often severely hampered by low activities, poor selectivities, narrow scope of arenes, and/or high substrate loadings," remarked Professor Han, who

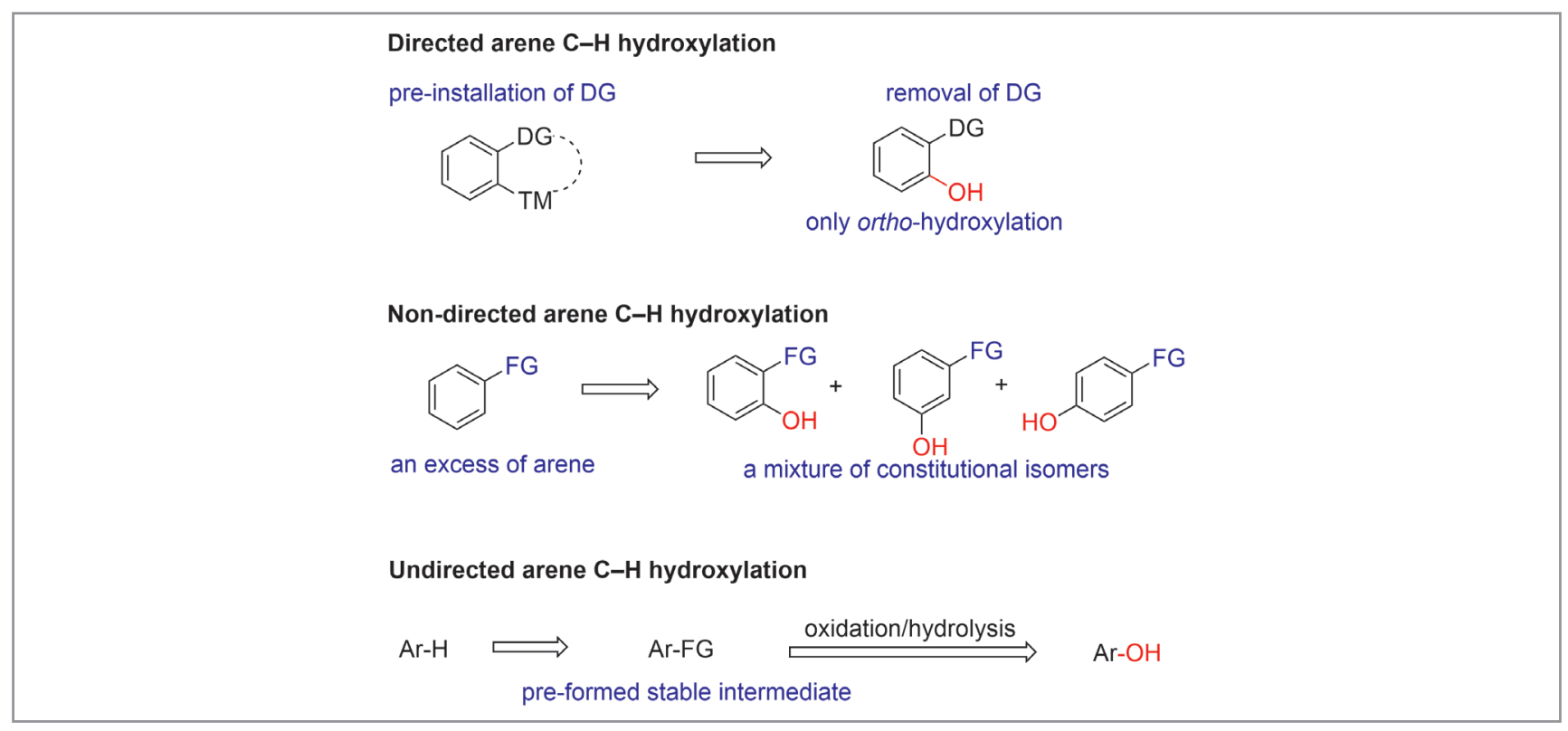

Scheme 1 State-of-the-art arene $\mathrm{C}-\mathrm{H}$ hydroxylation 


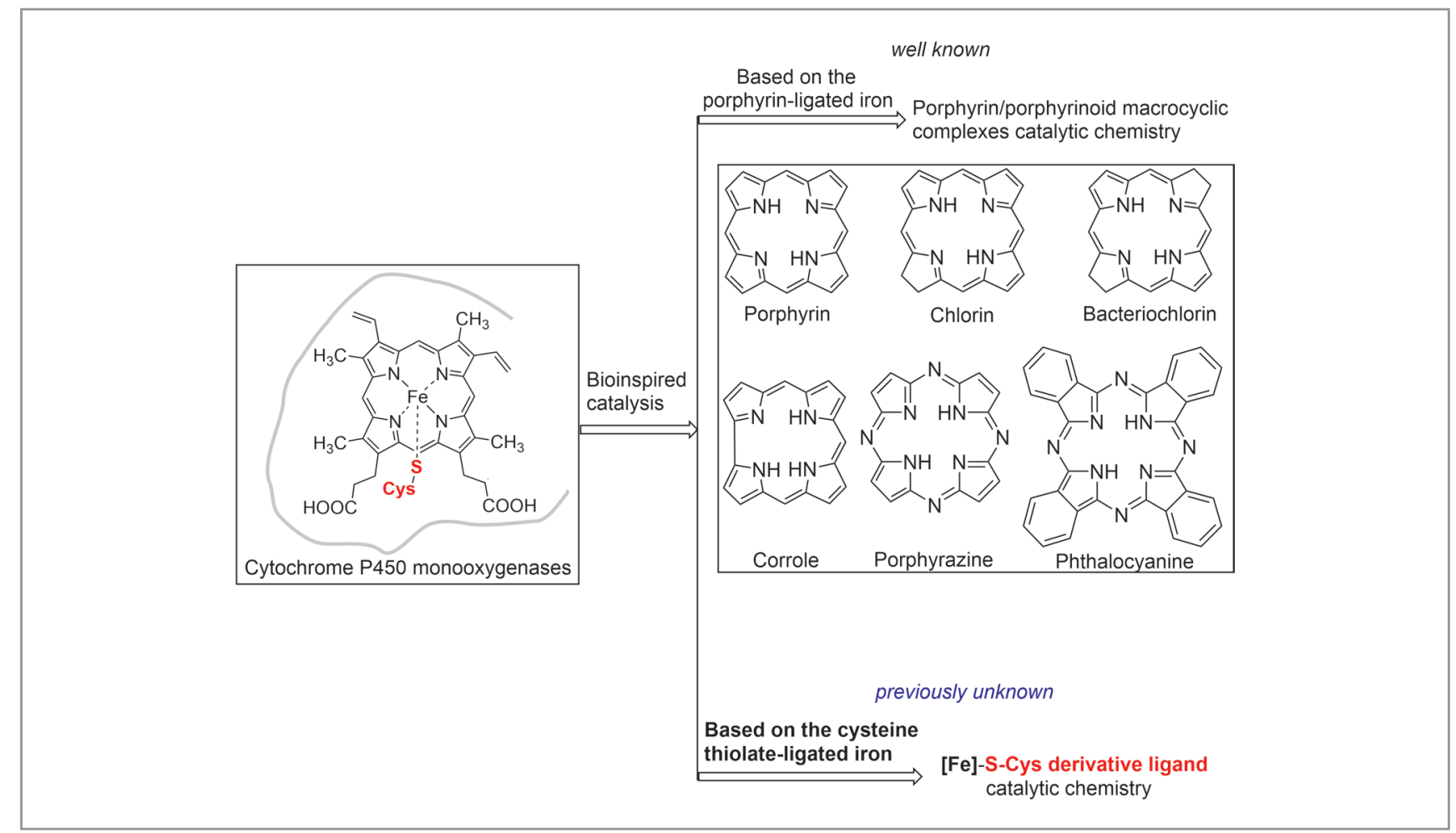

Scheme 2 Strategies for bioinspired cytochrome P450 catalysis

added: "In cytochrome P450 enzymes, the proximal ligand is the thiolate moiety of a residual cysteine, which coordinates to the haem iron center, which in turn is believed to control the oxidative activity of the enzymes and to facilitate $\mathrm{C}-\mathrm{H}$ oxidation. ${ }^{1}$ Unfortunately, the use of this property to design ligands for catalysis has been so far overlooked, probably due to the affinity of the sulfur atom for transition metals, which leads to a strong coordination and eventually to catalyst poisoning."

Professor Han continued: "Inspired by the proximal thiolate moiety of a residual cysteine ligand in cytochrome P450 enzymes, we designed an unprecedented iron-catalysed non-directed arene $\mathrm{C}-\mathrm{H}$ hydroxylation enabled by $\mathrm{L}$-cystine-derived ligands, which features excellent selectivities (Scheme 3). This transformation is defined by its broad substrate scope, excellent selectivity, good yields, and cost-efficient and environmentally friendly properties. Furthermore, it showcases compatibility with oxidation-sensitive functional groups such as alcohols, polyphenols, aldehydes, and even boronic acids. Notably, this method is well suited for the synthesis of polyphenols through multiple $\mathrm{C}-\mathrm{H}$ hydroxylations of arenes, and the late-stage functionalization of natural products and drug molecules." Professor Han concluded: "We anticipate that this novel method will find wide-ranging synthetic applications, including drug metabolite synthesis, and will also enable the achievement of important insights into biological pathways."

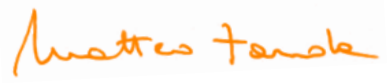

\section{REFERENCES}

(1) P. R. O. Montellano Cytochrome P450: Structure, Mechanism, and Biochemistry; Springer: Boston, 2005. 


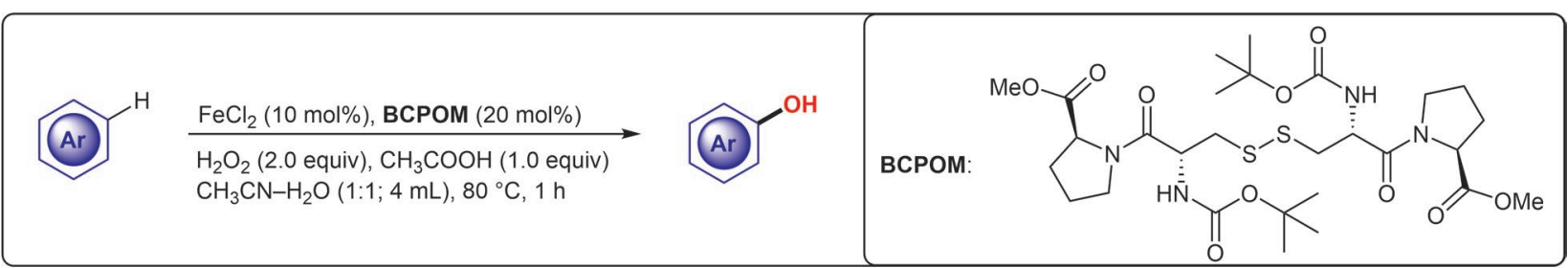

- Biologically inspired iron catalysis

- Highly selective oxidation of substituted arenes with diverse functional groups

- One-step hydroxylation of arenes without directing/protecting groups

- General (electron-deficient, electron-rich, and electron-neutral aryl ring)

- Compatibility with oxidation-sensitive functional groups $\left[\mathrm{B}(\mathrm{OH})_{2}, \mathrm{OH}(\mathrm{ArOH}, \mathrm{BnOH}), \mathrm{CHO}, \mathrm{CONH}_{2}\right]$

- Water as the only by-product<smiles>CC(=O)c1ccc(Cl)c(O)c1</smiles>

$57 \%$<smiles>COc1cc(OC)c(O)c(B(O)O)c1</smiles>

$75 \%$<smiles>CS(=O)(=O)Nc1ccc([N+](=O)[O-])cc1Oc1ccccc1O</smiles>

HO-Nimesulide $45 \%$ (RSM: $49 \%$ )<smiles>CC(C)c1ccc(O)c(O)c1</smiles>

$50 \%(2: 1)^{*}$<smiles>COc1cc(C(N)=O)ccc1O</smiles>

$70 \%$<smiles>COC(=O)c1cc(OC)cc(OC)c1O</smiles><smiles>O=Cc1cccc(O)c1O</smiles>

$55 \%$<smiles>COc1cc(CO)c(O)c(OC)c1</smiles>

$80 \%$<smiles>O=C(c1ccccc1)c1cc(O)c(O)cc1O</smiles>

$65 \%$<smiles>CC(C)OC(=O)C(C)(C)Oc1ccc(C(=O)c2ccc(Cl)cc2)cc1O</smiles>

HO-Fenofibrate $46 \%$ (RSM: $51 \%$ )<smiles>Cc1cc(OCC2CNC(=O)O2)cc(C)c1O</smiles>

HO-Metaxalone $70 \%$ (RSM: 17\%)

Scheme 3 Selected substrate scope 


\section{About the authors}

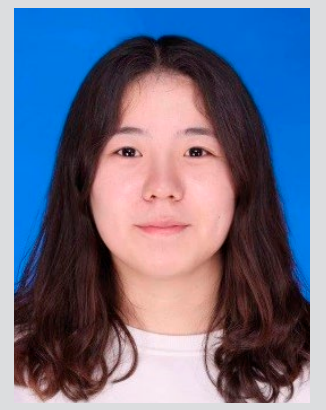

Lu Cheng was born and raised in Shanxi, P. R. of China. She earned her Bachelor's degree at Jinzhong University (P. R. of China). She joined Professor Wei Han's lab, Nanjing Normal University (P. R. of China), in 2017, where she started transition-metalcatalyzed $\mathrm{C}-\mathrm{H}$ functionalization. She earned her Master's degree in 2020.

\section{Cheng}

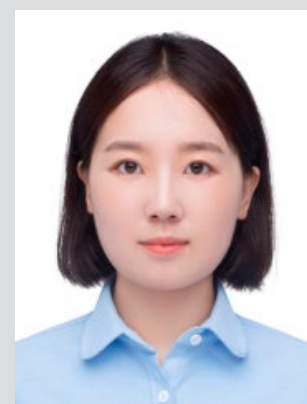

H. Wang

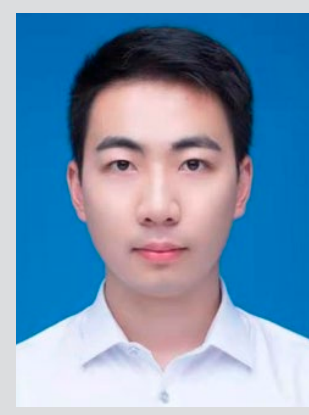

H. Cai

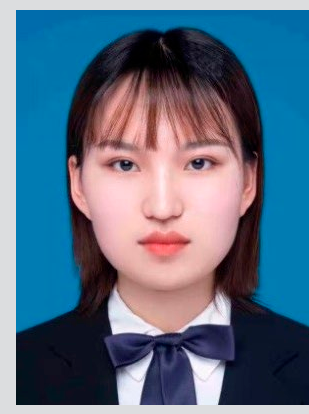

J. Zhang
Huihui Wang was born and raised in Shanxi, P. R. of China. She obtained an undergraduate degree from the Jinzhong University in Shanxi province (P. R. of China) in 2019. Currently, she is a third-year student in Prof. Wei Han's group at the Nanjing Normal University (P. R. of China). Her research interest is iron-catalyzed $\mathrm{C}-\mathrm{H}$ bond functionalization and its application in decoration of bioactive compounds.

Hengrui Cai was born and raised in Shandong, P. R. of China. He obtained an undergraduate degree from the Qingdao University of Science and Technology in Shandong province ( $P$. R. of China) in 2013. Currently, he is a third-year student in Prof. Wei Han's group at Nanjing Normal University (P. R. of China). His research interest is iron-catalyzed $\mathrm{C}\left(\mathrm{sp}^{3}\right)-\mathrm{H}$ bond heteroarylation and its application in decoration of bioactive compounds. of China. She is a senior undergraduate in the School of Chemistry and Materials Science, Nanjing Normal University (NNU, P. R. of China). In 2019, she joined Prof. Wei Han's group as a member of NNU college students' Elite training program and participated in the Provincial Training Programs of Innovation and Entrepreneurship for Undergraduates on
Jie Zhang was born in Henan, P. R. iron-catalyzed $\mathrm{C}-\mathrm{H}$ bond functionalization, which was rated as excellent at the end of the project.

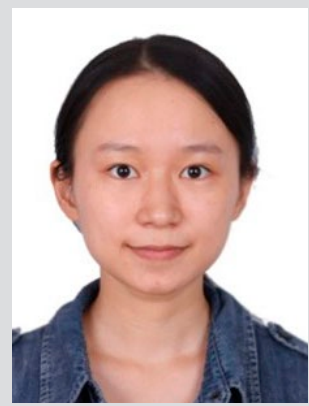

Xu Gong was born in Hunan, P. R. of China. She is a senior undergraduate of the School of Chemistry and Materials Science, Nanjing Normal University (P. R. of China). In 2019, she joined Prof. Wei Han's group at the same university and hosted a provincial college students' innovation and entrepreneurship training project on iron-catalyzed oxidation, which was X. Gong rated as excellent research.

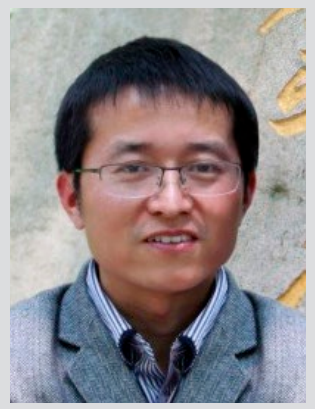

Wei Han received his B.Sc. in chemistry from the Wuhan Institute of Chemical Technology (P. R. of China) in 2005, and obtained his M.Sc. in applied chemistry from the Dalian University of Technology (P. R. of China) in 2008. In 2011, he earned his Ph.D. in organic chemistry, working with Prof. Herbert Mayr at LudwigMaximilians-Universität München (Germany). Subsequently, he started his independent career at Nanjing

Prof. W. Han Normal University (P. R. of China) and was promoted to full professor in 2018. From 2019 to 2020, he worked with Prof. M. Christina White at the University of Illinois Urbana-Champaign (USA) as a visiting scholar. His current research interests focus on the development of novel synthetic methodologies and bioinspired catalysis. 


\section{Switching On Prodrugs Using Radiotherapy}

Nat. Chem. 2021, 13, 805-810

Chemotherapy is extensively used in oncology, being highly efficient for cancer treatment. However, many commercially applied chemotherapeutic drugs have less-than-ideal selectivity for cancer cells and often do not spare normal healthy tissues/organs, thus giving rise to systemic toxicity effects in patients. The use of prodrugs is known to be an effective strategy to reduce these side effects and enhance selectivity. Prodrugs are typically chemotherapy drugs that have been chemically modified, such that they release the pharmacologically active agent upon chemical modification in vivo. Thus, when the prodrugs reach the tumor area, stimulus-triggered de-caging of the 'modification' takes place and releases the active drug, thus achieving precise tumor treatment.

"The stimuli used to activate prodrugs can be divided into two categories, namely internal stimuli and external stimuli," said Professor Jin Geng at Shenzhen Institutes of Advanced Technology, Chinese Academy of Sciences (P. R. of China), whose group has a strong interest in this research area. "Internal stimuli include enzymes over-expressed in cancer, or physiological parameters or aberrations found within the tumor microenvironment, such as $\mathrm{pH}$ and hypoxia. External stimuli often offer precise temporal and spatial control over site of action. For example, light, ultrasound, heat, and local molecular injections can trigger prodrug activation at the site of disease and at the desired time," he added.
Professor Geng said that since radiotherapy is an effective treatment strategy for inhibiting tumor growth, it is often used in combination with chemotherapy to treat patients suffering from advanced cancers. "Concomitant chemo-radiotherapy for malignant tumors originates from the concept of comprehensive treatment and has become a standard therapeutic method to prolong patients' survival time," he said, adding: "Currently used concomitant treatments use sensitizers to promote the effect of radiotherapy. However, the use of radiotherapy radiation sources, i.e. X-rays, as a source of stimuli to activate prodrugs, has only rarely been investigated."

In this collaborative work, the groups of Professor Geng and that of Professor Mark Bradley at the University of Edinburgh (UK) imagined an antitumor drug that could be converted into an X-ray-activatable prodrug with sufficient stability and significantly reduced toxicity compared to the naked drug, such that systemic toxicity issues can be overcome. Professor Geng said: "For patients receiving a dose of such a prodrug, the toxic drug molecules would only be generated at the tumor site, when receiving the X-ray treatment. Additionally, with the development of therapeutic X-ray techniques, precise radiation with high 3D resolution could be achieved, so that the prodrug activation region may be precisely controlled, therefore allowing the use of higher doses of prodrugs in patients, to further improve the treatment's efficacy."

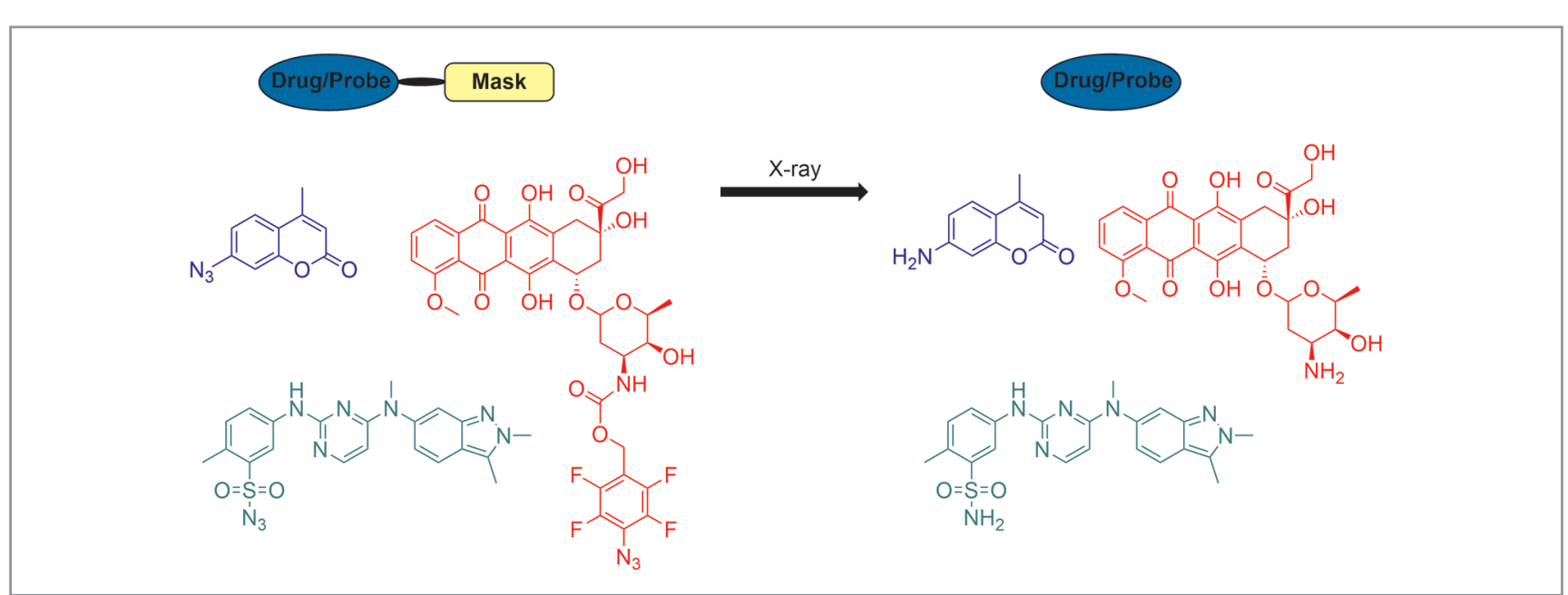

Scheme 1 A coumarin-based quenched fluorophore and pazopanib- and doxorubicin-derived model prodrug molecules were activated by $\mathrm{X}$-ray radiation 
Professor Bradley added: "Here, we have explored the possibility of using clinically utilized radiotherapy X-ray sources to activate antitumor prodrugs. In the early stage of this project, we conducted a wide-range screening of poten- tially activatable organic molecules that may react following $\mathrm{X}$-ray radiation. Fortunately, we found that sulfonyl azides and fluoroaryl azides can be converted into the corresponding sulfonamides and aromatic amines at clinically relevant doses of

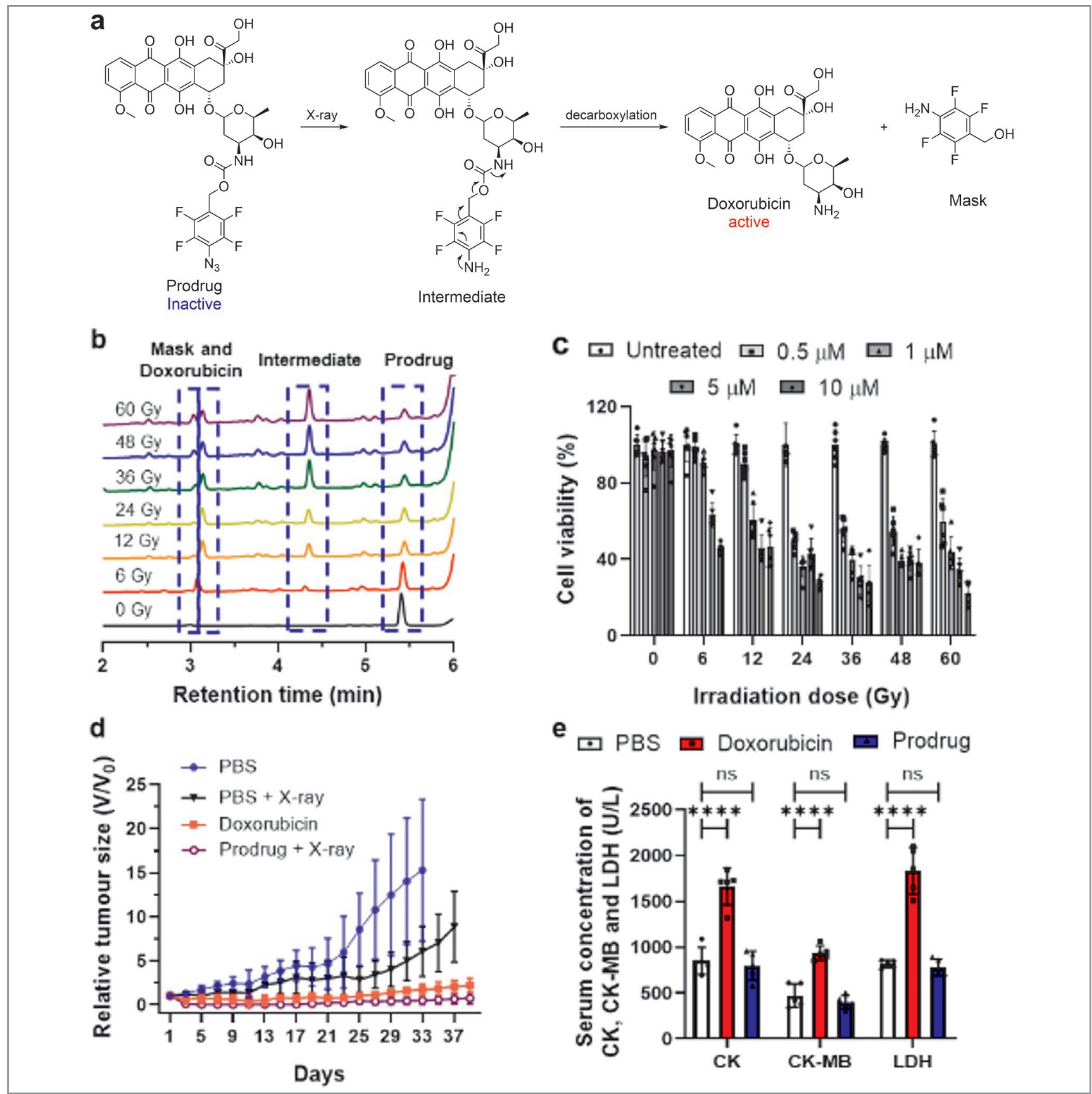

Scheme 2 (a) The reaction of the doxorubicin-based prodrug and mechanistic pathway for liberation of doxorubicin. The activation of the prodrug has been proved on (b) the molecular level, (c) cancer cell lines, and (d) animal models. (e) Biochemical markers CK, CK-MB and LDH levels in plasma showed that the prodrug strategy can effectively reduce side effects in mice. 
X-ray radiation with high efficiency. It is reported that X-ray radiation of aqueous solutions can generate reactive species such as hydroxy radicals, hydrogen radicals, and hydrogen peroxide, but here we propose that the azide reduction mechanism occurs through 'solvated electrons'."

To translate these findings to medical applications, the authors introduced a functional group onto antitumor drug molecules (and fluorescent reporters) to synthesize a series of prodrugs and quenched fluorophores. "We verified their activation efficiency, pharmacological activity and biosafety both in vitro and in vivo," explained Professor Geng. He continued: "We found the prodrugs reduce systemic toxicity while they were efficiently generated at the tumor site, significantly prolonging the survival time of tumor-bearing animals." Professor Bradley concluded: "We believe this X-ray activatable prodrug system could represent an important new modality in therapeutic oncology and open up a new era in targeted and directed cancer chemoradiotherapy."

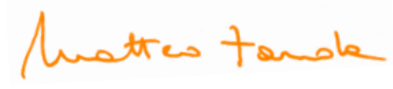

\section{About the authors}

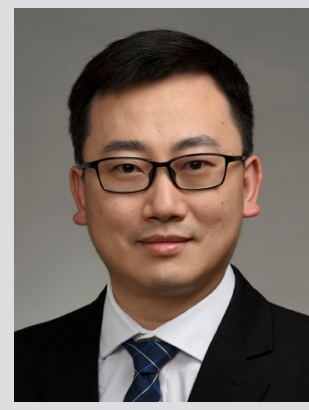

Jin Geng is a professor of chemistry at Shenzhen Institutes of Advanced Technology, Chinese Academy of Sciences (SIAT, P. R. of China). He took up his current position in 2019, following on from his appointment at the University of Edinburgh (UK) as a research fellow working with Professor Mark Bradley. He is the director of the centre for polymers in medicine at SIAT. He leads a diverse team of reProf. J. Geng searchers focusing on polymer chemistry, biomaterials, and biomedicine technologies, and conducts research and development of diagnostic technologies and innovative drugs for tumors and other major diseases.

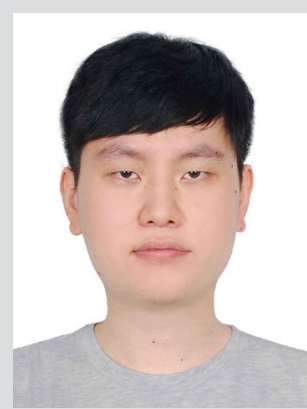

Dr. Y. Zhang

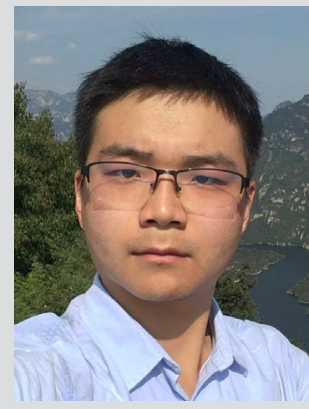

Dr. Q. Gao
Yichuan Zhang graduated from the University of Edinburgh (UK) in 2019 and is working as a postdoctoral researcher in Shenzhen ( $P$. R. of China). His research interests include chemical biology and polymer chemistry and he has achieved a series of outstanding outcomes in the field of cancer therapeutic drugs, prodrug activations, and live cell manipulations.

Quan Gao received his PhD in biochemistry and molecular biology from the Institute of Microbiology, Chinese Academy of Sciences (Beijing, P. R. of China) in 2019. His doctoral research focused on the antitumor mechanism of fungal secondary metabolites. He is now doing postdoctoral research at Shenzhen Institute of Advanced Technology, Chinese Academy of Sciences (Shenzhen, Guangdong, P.

R. of China) under Prof. Jin Geng and studying the antitumor effects of controlled intracellular polymerization. 


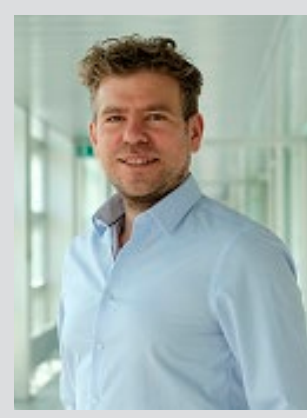

Prof. K. Neumann
Kevin Neumann is an Assistant Professor (tenure track) at Radboud University, The Netherlands. His research focuses on new principles for drug activation and delivery. In 2018, Kevin obtained his PhD at the University of Edinburgh (UK), under the supervision of Professor Mark Bradley. In his PhD, Kevin worked on tetrazine-mediated prodrug activation chemistry. It was during this time when Kevin joined the project of radiotherapy-mediated prodrug activation. For his postdoctoral studies, Kevin joined the group of Professor Jeffrey Bode at ETH Zurich, Switzerland. There, he worked on the total chemical synthesis of proteins and their biological evaluation.

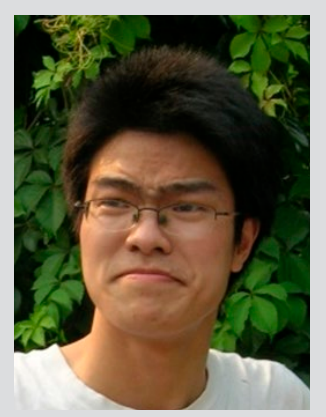

Hua Dong was born in 1985, in Nancheng, Sichuan Province (P. R. of China). He received his doctorate in physical chemistry from the Institute of Chemistry of the Chinese Academy of Sciences (P. R. of China) in 2012. After two postdoctoral studies at the University of Barcelona in Spain and the University of Edinburgh in the UK, he joined the School of Materials and Chemical Engineering at Chengdu Polytechnic University in 2018. At Dr. H. Dong present, he is mainly engaged in special immersion interface material design preparation and application research.

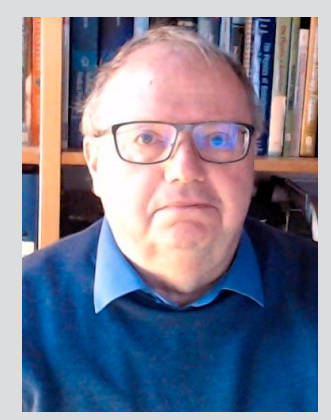

Hamish Porter is a medical radiation physicist who was Consultant Clinical Physicist and Deputy Head of Oncology Physics at Edinburgh Cancer Centre (UK). He studied chemistry and physics at Edinburgh University (UK) and has held postdoctoral and academic posts at the Universities of Stirling (UK), UMIST (Manchester, UK), London (ICR, UK), Carnegie MelIon University (USA), Oxford (Balliol College; UK) and Edinburgh (UK). OxProf. H. Porter ford projects involved the development of UV and X-ray photoelectron microscopy with Professor D. W. Turner F.R.S. He was 2011 Silvanus Thompson medallist of the British Institute of Radiology for developments in electron linear accelerators for cancer therapies. He has worked as a physics consultant to several private Radiation Oncology Centres and four University
Veterinary Oncology Centres. His present research centers on clinical radiobiology/radiochemistry of relativistic electron and proton beams.

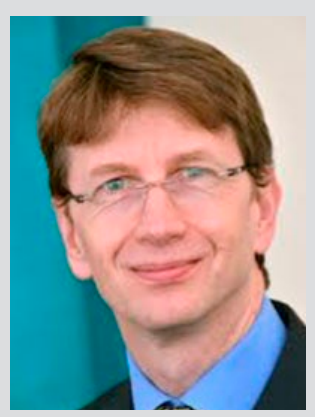

Mark Potter is a Consultant Colorectal Surgeon at the Western General Hospital, Edinburgh (UK). This is a dedicated Colorectal Unit, serving the population of Edinburgh and tertiary referral practice from all areas of Scotland. The Unit is one of the largest in Europe and has an international research reputation. He was awarded BSc in chemistry before reading medicine at the University of Edinburgh (UK). His MD thesis was looking for Mr. M. Potter novel ways of detecting colorectal cancer mutations in clinical
samples. He is an Honorary Clinical Senior Lecturer at the University of Edinburgh and Fellow of the Royal College of Surgeons of England and Edinburgh. He is a member of the European Society of Coloproctology (ESCP) Education Committee. His current research interests include translational studies for surgical technology, targeted chemotherapy and anastomotic leak.

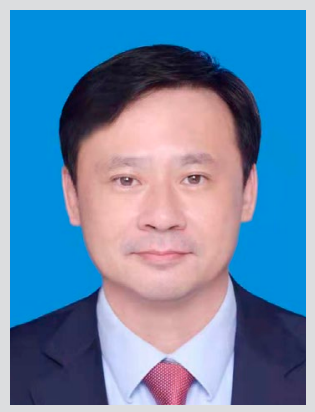

Hua Ren received his master's and doctoral degrees from The Beijing Concord Medical College (P. R. of China) in 2004 and 2010, respectively. He was a radiotherapist at Oncology Hospital of the Chinese Academy of Medical Sciences (P. R. of China, 1997-2021) and was hired as an associate professor at Southern University of Science and Technology (P. R. of China in 2020. His research interest includes cancer and radiation therapy.

David Argyle graduated from the University of Glasgow (UK) veterinary school and subsequently worked in general practice. He returned to Glasgow to complete a PhD in the Department of Veterinary Pathology and then worked as a lecturer and senior lecturer in clinical oncology in the Department of Clinical Studies. In 2002, he became associate professor of clinical oncology at the University of Wisconsin-Madison, USA. In 2005, he returned to the UK to take the William Dick Chair of Clinical Studies at the University of Edinburgh. On his return he set up the R(D)SVS Cancer and Imaging Centre. He in an RCVS and European Specialist in Veterinary Oncology, a Diplomat of the European College of Internal Medicine in Oncology and is co-scientific editor of the Journal of Veterinary and Compara- 
tive Oncology. Within the R(D)SVS he is the Dean of Veterinary Medicine and Head of School and is also the Deputy Head of The College of Medicine and Veterinary Medicine. He has overall responsibility for the School including its research arm, the Roslin Institute. In 2016, he was elected Fellow of the Royal Society of Edinburgh. In the same year, he was elected Fellow of the Royal College of Veterinary Surgeons (for meritorious contributions to veterinary research).

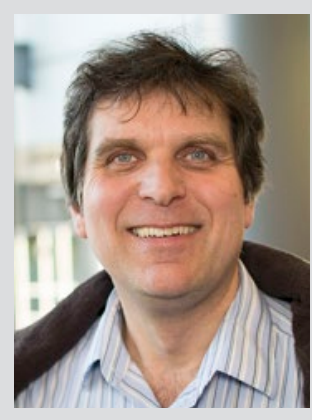

Prof. M. Bradley
Mark Bradley, based at the University of Edinburgh (UK), is a chemist by training but with a strong interdisciplinary ethos and translational mindset. He began his academic career in 1992 at the University of Southampton (UK) as a Royal Society University Research Fellow, where he worked in the area of combinatorial chemistry, co-founding Ilika Technologies. He moved to the University of Edinburgh in 2005 where over the years he has been co-founder of Edinburgh Molecular Imaging, DestiNA Genomics and most recently BioCativa. He has published some 400 papers and reviews and 25 patents and is an ERC Advanced grant awardee. 


\section{Coming soon}

\section{- Literature Coverage}

\section{Synthesis of Medicinally Relevant Oxalylamines via Copper| Lewis Acid Synergistic Catalysis}

\section{Literature Coverage}

\section{A Divergent Strategy for Site-Selective Radical Disulfuration of Carboxylic Acids with Trisulfide-1,1-dioxides}

- Literature Coverage

Enantioselective Synthesis of Ammonium Cations

\section{Further highlights}

\section{Synthesis Review: Covalently Templated Syntheses of} Mechanically Interlocked Molecules (by J. H. van Maarseveen and co-workers)

\section{Synlett Account: Unlocking the Synthetic Potential of} Light-Excited Aryl Ketones: Applications in Direct Photochemistry and Photoredox Catalysis (by L. Dell'Amico and co-workers)

\section{Synfacts Synfact of the Month in category "Metals in Syn- thesis": Enantioselective Cobalt-Catalyzed Alkene Hydro- alkylation}

Edito

Matteo Zanda

C.N.R. - Istituto di Scienze e Tecnologie Chimiche (SCITEC)

Via Mancinelli, 7, 20131 Milano, Italy

Editorial Assistant: Alison M. Sage, synform@outlook.com

\section{Editorial Office}

Senior Director, Operations:

Susanne Haak, susanne.haak@thieme.de

- Scientific Editor:

Selena Boothroyd, selena.boothroyd@thieme.de

Executive Editors:

Stefanie Baumann, stefanie.baumann@thieme.de

Giuliana Rubulotta, giuliana.rubulotta@thieme.de

Editorial Assistant:

Sabine Heller, sabine.heller@thieme.de

Marketing Director:

Malina von Pfeil, malina.vonpfeil@thieme.de

Typesetting:

Ulrike Holzwarth, Büro für Gestaltung, Stuttgart

- Postal Address: Thieme Chemistry Journals, Georg Thieme Verlag KG,

Rüdigerstraße 14, 70469 Stuttgart, Germany.

Homepage: www.thieme-chemistry.com

\section{Publication Information}

Synform will be published 12 times in 2022 by Georg Thieme Verlag KG, Rüdigerstraße 14 70469 Stuttgart, Germany, and is an additional online service for Synthesis, Synlett and Synfacts.

\section{Product Names}

Product names which are in fact registered trademarks may not have been specifically designated as such in every case. Thus, in those cases where a product has been referre to by its registered trademark it cannot be concluded that the name used is public domain. The same applies to labels, names or other signs.

Ordering Information for Synthesis, Synlett and Synfacts

The Americas: Thieme New York, 333 Seventh Avenue, New York, NY 10001, USA. Via e-mail: customerservice@thieme.com

Via website: www.thieme-chemistry.com

Phone: +1 212760 0888; Fax: +1 2129470108

Order toll-free within the USA: +18007823488

Europe, Africa, Asia, and Australia: Georg Thieme Verlag KG, Rüdigerstraße 14 70469 Stuttgart, Germany.

Via e-mail: customerservice@thieme.de

Via website: www thieme-chemistry.com

Phone: +49 7118931 421; Fax: +49 7118931410

Current list prices are available through www.thieme-chemistry.com.

\section{Online Licensing Information}

The online versions of Synform as well Synthesis, Synlett, Synfacts and SynOpen are available through www.thieme-connect.com/products/ejournals/journals) where it is also possible to register for a free trial account. For information on multi-site licenses and pricing for corporate customers, as well as backfiles, please contact our regional offices:

The Americas: esales@thieme.com, phone: +1 2125844695

Europe, Africa, Asia (ex. India), and Australia: eproducts@thieme.de,

phone: +497118931407

India: eproducts@thieme.in, phone +91 1204556600

Manuscript Submission to Synthesis, Synlett, and SynOpen

Manuscript submissions will be processed exclusively online via

http://mc.manuscriptcentral.com/synthesis, http://mc.manuscriptcentral.com/synlett and http://mc.manuscriptcentral.com/synopen, respectively. Please consult the Instructions for Authors before compiling a new manuscript. The current version and the Word template for manuscript preparation are available for download at www. thieme-chemistry.com.

\section{Ownership and Copyright}

(c) 2022. Thieme. All rights reserved.

This publication, including all individual contributions and illustrations published therein, is legally protected by copyright for the duration of the copyright period. Any use, exploitation or commercialization outside the narrow limits set by copyright legislation, without the publisher's consent, is illegal and liable to criminal prosecution. This applies in particular to photocopy reproduction, copyright, cyclostyling, mimeographing or duplication of any kind, translating, preparation of microfilms, and electronic data processing and storage (CD-ROM, DVD, USB memory stick, databases, cloud-based service, ebook and other forms of electronic publishing) as well as making it available to the public (e.g. internet, intranet or other wired or wireless data networks), in particular by displaying on stationary or mobile visual display units, monitors, smart phones, tablets or other devices by download (e.g., e-pub, PDF, App) or retrieval in any other form.

Copyright Permission for Users in the USA

Authorization to photocopy items for internal or personal use, or the internal or persona use of specific clients, is granted by Georg Thieme Verlag KG Stuttgart . New York for libraries and other users registered with the Copyright Clearance Center (CCC) Transactional Reporting Service; www.copyright.com. For reprint information in the USA, please contact: journals@thieme.com 